\title{
Kant and the Turn to Romanticism
}

Vinod Lakshmipathy

\section{Introduction}

$I^{\prime}$ $\mathrm{t}$ frequently happens in philosophy that a philosopher, in trying to resolve a long-standing dispute between two opposing schools of thought, comes 1 up with a schema that not only resolves the targeted dispute, but in addition necessarily imposes a residual set of regulations and norms, to which it had to subscribe in its attempt to solve the dispute, given its own presuppositions and points of departure. This residual set of norms is then viewed by the subsequent generation of thinkers, who start off their philosophy from a slightly different set of presuppositions, as being superfluous to what they conceive as the real project of the previous thinker. Hence, these subsequent philosophers build their philosophy by fundamentally modifying the stance of the previous thinker, all the while acknowledging the resolution of the dispute the latter carried out in his philosophy. One can view this process of fundamental shifts in orientation as the process of transition from one revolution to another in the history of philosophy.

What is mentioned above is most true of Kant's critical project and the German Romanticism and Idealism that grew out of it. Kant's basic project can be seen as an effort to resolve the conflict between dogmatism (especially, Leibnzian) and skepticism (especially, Humean). Kant's Critique of Pure Reason, which sought to set limits to human reason, argued against the dogmatists that one cannot claim to know what lies beyond the drawn limit, and it argued against the skeptics that we have synthetic a priori knowledge independent of all experience, a kind of knowledge which makes all our experience possible. To make this argument, Kant had to resort to what the Romantics called "dualisms." Kant had to make distinctions like that between the "noumena" and the "phenomena," the "intellectual" and the "sensible," the "regulative" and the "constitutive" uses of reason, among others. One of the main motivations behind making these key distinctions is to make room for buman freedom, which for Kant, is the necessary condition of morality. For the Romantics like Schelling, even though Kant had taken the essential steps to indicate the finitude of human reason, and therefore had made progress in resolving the long-drawn dispute between dogmatism and skepticism, the vestiges of these steps appeared as the non-desirable presence of dualisms in the Kantian system. For the Romantics, it is precisely these dualisms that render the Kantian system incomplete. Their complaint was that Kant could never satisfactorily explain the interaction between the domains, noumena and 
the phenomena, which suggested an impasse in the Kantian system. With this complaint, the Romantics seemed to gesture in favor of the pre-Kantians, however not to side with them. They replaced the old dogmatism with a new kind of "dogmatism," which relied on an "organic" concept of nature to get rid of the Kantian dualisms. Ironically, the Romantics' organic concept of nature is inspired by Kant's discussion of "natural purpose" in the Third Critique. The current essay will trace this shift by following how the organic concept of nature can get rid of the Kantian dualisms, and in doing so, what Kantian maxims it violates and what it does not violate. In the end, we will also briefly consider the implications of this Romantic turn for the status of freedom, by looking at some passages in Schelling's treatise on freedom.

\section{A Note on Kant's Dualisms}

Let us briefly consider the distinction between the noumena and the phenomena. Kant says in the First Critique, "Appearances, so far as they are thought as objects according to the unity of categories, are called phenomena. But if I postulate things that are mere objects of understanding, and which, nevertheless, can be given as such to an intuition, although not to one that is sensible . . . such things are entitled noumena." 1 Phenomena and noumena correspond respectively to the world of senses and the intelligible world of understanding. Only the sensible entities can be known; the intelligible entities can only be thought. The forms of intuition, space and time, and the categories of understanding work together in presenting the sensible, phenomenal world. On the other hand, the noumenon is "a thing so far as it is not an object of our sensible intuition." 2 More positively, we can presuppose a special mode of intuition — namely the intellectual — and we can understand by the noumenon, an object of non-sensible intuition. ${ }^{3}$ For Kant, the possibility of all experience, that is, the possibility of a priori synthetic judgments rests on how the individual categories of understanding interact with the pure forms of sensibility, space and time. However, Kant in the First Critique, is unclear about how exactly the two faculties of sensibility and understanding, come to be united, or how they spring from the same root. ${ }^{4}$

This problem is indirectly related to that of the interaction between phenomena and noumena. This interaction is required by Kant to resolve the third antinomy of pure reason. The thesis of this antinomy states that, "Causality in accordance with the [mechanical] laws of nature is not the only causality from which the appearances of the world can one and all be derived. To explain these appearances it is necessary to assume that there is also another

\footnotetext{
1 Immanuel Kant, Critique of Pure Reason, trans. by Norman Kemp Smith (New York: Palgrave Macmillan, 2003), A249.

2 Ibid., B307.

${ }^{3}$ Ibid.

${ }^{4}$ Kant gives a prominent role to the faculty of "imagination" in providing this unity, more so in the A edition than in the B edition. However, the status of imagination as the "blind but indispensable function of the soul" is left in obscurity in Kant's architectonic.
} 


\section{THE TURN TO ROMANTICISM}

causality, that of freedom." 5 The antithesis states that, "There is no freedom; everything in the world takes place solely in accordance with the laws of nature." 6 Kant resolves this antimony by holding that both thesis and antithesis can be rendered true, if we keep in mind that the former is true in the noumenal realm, and the latter in the phenomenal realm. Thus Kant makes room for buman freedom in (or beyond) a world where nature follows mechanical laws of cause and effect. Correspondingly, there are two separate domains. The ontological specialty of human beings is that there is in "man a power of selfdetermination, independently of any coercion through sensuous impulses."7 Human reason creates for itself the idea of spontaneity, which corresponds to the power of beginning a state spontaneously. ${ }^{8}$ This power of reason accounts for human freedom - the freedom to transcend the domain of the phenomenal, as it were. However, once a state is begun spontaneously, the consequent chain of actions is subject to the mechanical laws of the natural world of phenomena. That is, an effect "notwithstanding its being thus determined in accordance with nature, [may at the same time] be grounded in freedom." Hence the peculiarity of human beings is that they are able to "bridge" the two realmsnoumena and phenomena. But Kant is unclear about how exactly this interaction is possible. There is an irreducible dualism.

Finally, let us take up the distinction between the "regulative" and the "constitutive" uses of pure reason. The regulative principle is one of the "greatest possible continuation and the extension of experience, allowing no empirical limit to hold as absolute. Thus it is a principle of reason which serves as a rule, postulating what we ought to do in the regress, but not anticipating what is present in the object as it is in itself, prior to all regress." 10 Because the natural sensible world contains no completeness, the regulative principle provides the impetus for extending our knowledge of this world. It instructs how the empirical progress ought to be carried out so that we can strive to secure the complete concept of the object, even though this completion cannot be attained, since in the mechanical domain of nature (phenomenal realm) one cannot reach the absolutely unconditioned. Thus the regulative principle is a principle of better approximation, which applies to relations of existence.

The constitutive principle, on the other hand, tells us what the object is; it helps constitute the object. The constitutive principle makes experience possible. Pure reason cannot supply this principle. The principle corresponds to the phenomenal world, as it is possible only due to the joint operation of sensibility and understanding. The regulative principle can prescribe the systematic unity as a "unity in nature, which is not known merely empirically but

\footnotetext{
${ }^{5}$ Ibid., A444. In the First Critique, this freedom is called the "transcendental freedom," which is the ground of the "moral freedom" expounded in the Second Critique.

${ }^{6} \mathrm{Ibid}, \mathrm{A} 445$.

${ }^{7}$ Ibid., B562.

8 Ibid., A532.

${ }^{9}$ Ibid., B564.

${ }^{10}$ Ibid., A509.
} 
is presupposed a priori."11 The common error of the dogmatists, Kant argues, consists in taking the regulative principle of the systematic unity of nature as being a constitutive principle. Kant writes, "The investigation of nature takes its own independent course, keeping to the chain of natural causes in conformity with their universal laws."12 But we must assume that there is a systematic unity of nature, which would provide the impetus to extend our knowledge of nature. Thus, again we see a peculiar interaction between the regulative employment and the constitutive employment of reason. One of the main goals of a critique of reason is to ensure that these two uses of reason are never confused for one another.

\section{Organic Concept of Nature}

First, we will briefly consider an important section of the Third Critique, section 65, where Kant gives an instance in which only the regulative principle is valid. This discussion will help us make a transition into the Romantics' concept of nature. Kant, in this section, discusses "natural purpose." He talks about a causal combination in accord to a concept of reason of purposes, which when regarded as a series can run either forwards or backwards. This combination stands in contrast to the unidirectional causal combination thought merely by the understanding, where effects of causes cannot in turn be causes of the latter. ${ }^{13}$ Kant claims that the former kind of formal combination can be found in human art. For something to have natural purpose or teleology depends on two facts: (1) the parts of that thing (as regards their presence and form) are only possible through their reference to the whole. ${ }^{14}$ The thing has an organic unity, where each part derives its meaning and place by virtue of being part of the whole. But this condition can also be satisfied by something like a machine. Hence, this condition alone is not enough. Therefore, Kant adds another condition for natural purpose: (2) the parts of the things should combine in such a way in the unity of the whole that they are reciprocally cause and effect of each other's form. ${ }^{15}$ The thing under consideration would be a self-sufficient one, and also self-generating, that is, it would have "formative" power. It would need no external cause or agent to design it. Here the "connection of effective causes may be judged as an effect through final causes." 16 In such an "organic instrument," which is not a mechanical instrument, every part exists by the means, and for the sake of, the other parts and the whole. There is internal, natural perfection in such an instrument, and it is not "analogous to any physical, i.e. natural, faculty known

\footnotetext{
11 Ibid., A693.

12 Ibid., B722.

${ }^{13}$ Immanuel Kant, Critique of Judgment, trans. by J.H. Bernhard (New York: Prometheus Books, 2000), 276.

14 Ibid.

${ }^{15}$ Ibid., 277.

${ }^{16}$ Ibid.
} 


\section{THE TURN TO ROMANTICISM}

to us; nay even, regarding ourselves as, in the widest sense, belonging to nature."17

Now, the decisive difference between the Romantics and Kant is this: unlike the Romantics, Kant wants to ascribe only a regulative validity, but not a constitutive validity to the concept of a natural purpose. He says, "The concept of a thing as in itself a natural purpose is therefore no constitutive concept of understanding or of reason, but it can serve as a regulative judgment, to guide our investigation about objects of this kind ..." 18 The Romantics, on the other hand, accept the above characterization of the "organic instrument," only to apply it constitutively to nature as a whole. Thus they violate Kant's maxim. This violation is so crucial that it not only redefines the essence of "nature," but it also gives a different meaning to human existence. The dualisms of the Kantian system are overcome; the problems of dualism are dissolved rather than solved. Violating the above Kantian maxim amounts to reinstalling a different sort of "dogmatism," which involves a kind of teleology, whose end or purpose is derived from within (an intrinsic teleology), not from without (the kind some of the pre-Kantian dogmatists subscribed to). We have to spell this out. Also, we have to follow the subtle, but decisive shifts introduced into the Kantian system by the Romantics' doctrine. How do these shifts avoid going back to a pre-critical stance? How do they still respect a sense of finitude that was introduced by Kant's critique? ${ }^{19}$ In what senses do they transgress the Kantian limits?

For Kant, philosophy should remain within the bounds of possible experience. But one can ask: what is the status of Kant's own philosophy? Are the words that make up the Critique of Pure Reason derived a priori synthetically? Does Kant know them or merely think them? This "meta" question points to an incompleteness in Kant's system, which the Romantics and Idealists sought to complete. The "meta" question points to the inevitable problem of the need to transcend the limits one has drawn in drawing this very limit. Schelling expresses his dissatisfaction with Kant's philosophy by stating that it is a prejudice of the latter to suppose that reason is found only in humans. For Schelling, "the conviction that all thought and knowledge are completely subjective and that Nature altogether lacks reason and thought,"20 leads to the view that nature can be understood purely mechanically, notwithstanding the dynamic factor Kant introduced into nature. The main presupposition which Schelling rejects is the conviction that one can start off one's philosophy without first questioning where reason belongs. Kant, who in a sense, gave the most mature formulation of the Cartesian beginning of modern philosophy never questioned "reason" to be the "subjective" possession of human beings

\footnotetext{
${ }^{17}$ Ibid., 280.

18 Ibid.

19 The subscription to a sort of "phenomenological" method ensures that this finitude is respected, at least in a certain sense. To be discussed below.

${ }^{20}$ F. W. J. von Schelling, Of Human Freedom, trans. by James Gutmann (Chicago: The Open Court Publishing Company, 1936), 3.
} 
alone. ${ }^{21} \mathrm{It}$ is only from this standpoint that Kant understands and evaluates the history of philosophy, in providing a critique of pure reason. For Schelling, it is all right to provide a critique of reason, but it is reckless to assume that reason is possessed only by humans, because it is precisely the question concerning the essence of human beings that is problematic. Reason, then, has to be emancipated from its subjective underpinnings, which would result in a revolution of the "contrast between Necessity and Freedom, in which alone the innermost center of philosophy comes to view." 22 What has to be shown is that freedom is not exclusively a property of human beings, but that freedom determines the essence of human beings as the highest manifestation of the powers inherent within nature. In this sense, humanity would be the telos of nature.

The implications of this fundamental turn effected by the Romantics to the Kantian starting point are many. Schelling launches his attack against Kant by expressing his dissatisfaction that the Kantian system allows only for a "practical" freedom, and not for a "theoretical" one. Inspired by Fichte's move, which completely liberated the "ego," Schelling seeks to gain a "higher standpoint, above the negativity which is characteristic of [Kant's] theoretical philosophy." 23 He writes:

But it will remain strange that Kant, after first distinguishing the things in themselves from appearances only negatively, as being independent of time, and later, in the metaphysical explications of his Critique of Practical Reason, treated independence-of-time and freedom as correlative concepts, did not proceed to the thought of transferring this only possible positive conception of per-seity to things. ${ }^{24}$

Here we see a precise formulation, by Schelling, of that peculiar interplay between concepts that occurs during philosophical revolutions. Why Kant did not "transfer" the positive concept of freedom to things (nature) is precisely because he wanted to avoid collapsing back into the dogmatism that he had set out to critique. Schelling, on the other hand, believes that the transfer is possible; however this does not necessarily imply that one just falls back into the ways of the old dogmatism. Schelling agrees with Kant that the kind of dogmatism of a Spinoza or a Leibniz must be avoided. But this does

21 In modern philosophy, running parallel to this supposition that reason is the subjective possession of human beings alone is the assumption that nature "lacks a living basis." See ibid., 30.

22 Ibid., 3. Schelling writes further, "The thought of making freedom the sum and substance of philosophy has emancipated the human spirit in all its relationships $\ldots$ and has given to science in all its parts a more powerful reorientation than any earlier revolution." See ibid., 25.

${ }^{23}$ Ibid., 25.

${ }^{24}$ Ibid. Emphasis added. 


\section{THE TURN TO ROMANTICISM}

not mean that one has to necessarily take Kant's route. Kant, in a sense, was too keen to avoid dogmatism that he did not see that not every kind of dogmatism is bad. It is not dogmatism per se which has to be avoided, but only a certain manifestation of dogmatism. Even dogmatism can be saved if it is made to respect a certain awareness of buman finitude, an awareness the spirit of which is derived very much from Kant's own philosophy. What I am arguing is this: the pre-Kantians (including skeptics like Hume) and Kant shared the same starting point or presupposition, which Schelling describes as completely "subjective." 25 Once philosophy begins with this unquestioned presupposition, it would be dangerous and metaphysically dogmatic to make a priori ontological claims about the world and human existence. Kant was right in seeing this danger, and in reminding us of the need to respect a sense of human finitude. However, for the Romantics, Kant still shared the same starting point as his predecessors. Once a shift has been made in such a way that philosophy respects human finitude and it does not begin with presuppositions about "human subjectivity," then even dogmatism cannot pose a threat. One then is free to engage in metaphysical speculations. This move away from Kant's philosophy, which still maintains a sense of human finitude, is what I want to describe as "phenomenological." 26 It is also this move which avoids the thwarting "meta" question that Kant had to face. The rest of the essay will be spent in describing this turn, which would provide us an account of the Romantics' concept of nature.

One of the main characteristics of this phenomenological turn is as follows: it pays more attention to the "how" of the concepts than to the "what," which is apparent in its contention that depending on how one understands dogmatism one can even go on to save it. This implies a marked break with the Kantian philosophy of "thing in themselves." Kant argued that we cannot know the thing in themselves in order to stay clear of the dogmatists. The Romantics argued for a much freer relation to things in themselves. We cannot know the latter in the sense that the early dogmatists thought we could. Instead, when the proper essence of humans is brought out we see that we not only know about things in themselves, but we encounter them in such a way that the sort of pre-Kantian dogmatic knowledge is not only seen to be impossible, but also undesirable. The latter kind of knowledge, because it was

${ }^{25}$ Descartes, who in many respects inaugurates modern philosophy, gives an explicit articulation of this starting point for philosophy.

${ }^{26}$ One must differentiate the Romantics' phenomenological method from that of the Husserlian one. The latter, unlike the Romantics' method, seeks to describe phenomena as they present themselves to buman experience, although it does not return to the Kantian presuppositions about "human subjectivity." The latter kinds of presuppositions are what make Kantian and pre-Kantian versions of philosophy essentially "epistemological," whereas Husserlian phenomenology is not so much concerned with knowledge as it is with the finite human experience of the world. On the other hand, Hegel's "phenomenology" is much closer to the Romantics' sense of phenomenology, and is a result of a consistent and complete development of the latter. Hegel's extreme monism recognizes the "Absolute Spirit" as the only phenomenon, the self-unraveling in gradual steps of which is the coming-to-presence of reason in history and the object of all knowledge. 
based "subjectively," makes the meta-error of wanting to elevate itself "above" the domain it wants to gain knowledge of. But if everything-including human beings-belonged to one self-sufficient system then there would be no "meta" problems of having to elevate oneself "above" the system one is concerned with. I argue that this notion of a self-sufficient system is that which seeks to retain a certain gesture of human finitude as it is found in Kant. It is also what inaugurates a phenomenological method for philosophy, which primarily seeks to know that which is already there, that is, that which already presents itself. First, there is the phenomenon-here, in the form of a completed selfsufficient system-which manifests itself, and then there is the process by which the phenomenon comes to its own self-realization. Herein lies the Romantics' notion of finitude. Later, this phenomenological method is given a more explicit and mature formulation in the writings of Hegel.

We have already encountered this notion of a self-sufficient system in Kant's discussion of "natural purpose." 27 For the Romantics, the system in its completeness is already given. What remains to be unfolded is the process of becoming, in which the details of the system, which have hitherto been contained in an implicit manner, are laid out gradually, and made more and more explicit. However, this process of making-explicit does not smuggle in some extraneous element, which was not initially present within the system. This is the antidualistic, anti-meta notion of finitude. The process of becoming where the elements of the system unfold themselves, that is, come to realize themselves more and more concretely, is nothing but reason unfolding itself. Reason, therefore, is not some special faculty possessed by humans alone, but rather it is the unfolding of the one complete system. Schelling remarks:

It can be readily seen that in the tension of longing necessary to bring things completely to birth the innermost nexus of the forces can only be released in a graded evolution, and at every stage in the division of forces there is developed out of nature a new being whose soul must be all the more perfect the more differentiatedly it contains what was left undifferentiated in the others. It is the task of a complete philosophy of nature to show how each successive process more closely approaches the essence of nature, until in the highest division of forces the innermost center is disclosed. ${ }^{28}$

By shifting the locus of "reason" from human subjectivity to a loftier, grander notion of system which encompasses the human subject, Schelling is on his way to give a philosophy of becoming (history).

The above quotation from Schelling also demonstrates how in the Romantics' view, quantitative difference can account for qualitative difference.

${ }^{27}$ See 6-7 above.

${ }^{28}$ Schelling, op cit., 37. Emphasis added. 


\section{THE TURN TO ROMANTICISM}

This point is very important for our purposes because one way to look at the residual dualisms of the Kantian system is to see them as being indicative of irreducible qualitative differences, like that between "noumena" and "phenomena," "freedom" and "mechanical causality (nature)" etc. But, if through a process of "graded evolution," a "new being" can be created (by a process of creative leap), then one can view both nature and human beings as differing only in a "quantitative" manner, which would also account for the "qualitative" difference between them. Hence, there would be no need to posit two different spheres in order to account for the latter kind of difference. In this way, all the oppositional dualisms that plague Kant's system are seen in a new light as more or less elaborate constituents of the same single whole.

Next, we can note that the notion of an already-given completed system violates a particular maxim of the regulative use of reason of the Kantian system. For Kant, as we have seen, the regulative use ensures certain open-endedness in the system. This open-endedness is vital to introduce his notion of human finitude. But the Romantics violate the regulative principle of Kant by borrowing the latter's notion of "natural purpose" to arrive at their notion of an organic concept of nature. Schelling expresses this notion in the following way: "In the cycle whence all things come, it is no contradiction to say that that which gives birth to the one is, in turn, produced by it. There is here no first and no last, since everything mutually implies everything else, nothing being the 'other' and yet no being being without the other . . . the concept of becoming is the only one adequate to the nature of things." 29 Schelling here is pointing to the idea of an intrinsic teleology. There is an inherent purposiveness to nature, which is to realize itself in itself. The purpose does not lie beyond nature. Schelling is not trying to prove the existence of a supernatural being or some occult substance that gives purpose to nature. Also, as Frederick Beiser notes, for the Romantics, "the idea of a natural purpose does not necessarily imply intentionality, that is, the attribution of a will to a living thing. To state that an object is a natural purpose is not to assume that there is some intention behind its creation, still less that there is some kind of will within the object itself." 30 Further, this "non-subjective" dogmatism of the Romantics avoids all sorts of reductive materialism. If nature is an organic unity, irreducible to it parts, each of which gets its intelligible place only within the whole, then materialism is avoided, which contends that the parts can be investigated as self-sufficient entities. ${ }^{31}$ In these respects, the new dogmatism of Romanticism stays true to a notion of finitude, and hence in gesture agrees with Kant's critique of dogmatism.

But the new dogmatism still goes beyond Kant in an important respect in that it ascribes purposiveness to nature. The concept of natural purpose is employed constitutively. Kant wanted to remain agnostic about whether there are functions and processes in nature that are reducible to mechanical causes.

\footnotetext{
${ }^{29}$ Ibid., 33.

${ }^{30}$ Frederick C. Beiser, The Romantic Imperative: The Concept of Early German Romanticism (Cambridge, Massachusetts: Harvard University Press, 2003), 161-162.

${ }^{31}$ Ibid., 162.
} 
For him, the concept of teleology is a useful device for human beings to investigate and explain nature. We cannot go beyond the regulative to a constitutive reason because of the limits of human reason. Kant writes:

We can in no way prove the impossibility of the production of organized natural products by the mere mechanism of nature, because we cannot see into the inner ground of the infinite multiplicity of the particular laws of nature, which are contingent for us since they are only empirically known ... whether there lies at the basis of things which we must necessarily judge as properly natural purposes, a quite different kind of original causality, which cannot be contained in material nature or in its intelligible substrate, viz. an architectonic Understanding - this is a question to which our Reason . . . can give no answer whatever. ${ }^{32}$

For Kant, it is just as certain for us that "the mere mechanism of nature can furnish no ground of explanation of the production of organized beings," 33 even though, for all we know, organisms could still be produced by mechanism.

The non-subjective approach of the Romantics not only ascribes a function and process to the organic, but also a force, "a different kind of original causality" or causal agency, whose manifestations are observed in the process of becoming, which constitutes the essence of all natural processes. Although they do not have to necessarily rely on a supernatural being, their dogmatism still gives an ontological status to the concept of natural purpose by ascribing a constitutive status to the concept of teleology. Thus, for instance, there is no more strict demarcation between mind and body; the former is seen as a more complex organization of the living forces already manifest in body. Similarly, the gaps between the "subjective" and the "objective," "idealism" and "realism," are bridged. ${ }^{34}$ A mechanical explanation of the interaction of the inorganic forces in nature is possible because the inorganic is nothing but a limiting case of the organic. By attributing the same power of life that vitalized the mind into matter, the Romantics went beyond Kant's agnosticism, which was content in asserting that mere mechanism was not enough to explain matter. Schelling argues, "All nature tells us that it is no wise the product of mere geometric necessity; not sheer, pure reason, but personality and spirit are in it." 35 Everything, including human beings, belongs to nature, and each

\footnotetext{
32 Kant, Critique of Judgment, 296-297.

${ }^{33} \mathrm{Ibid}, 297$.

34 Schelling takes Leibnizian "idealism" as one-sided and incomplete as Spinoza's "realism." He writes, "Idealism, if it is not grounded in vital realism will become just as empty and attenuated a system as the Leibnizian... Idealism is the soul of philosophy; realism is its body; only the two together constitute a living whole." See op cit., 30.

35 Ibid., 75.
} 
"organism" is a manifestation of a particular degree of complexity of one and the same living force. The latter is manifest even in elementary forms of matter, as it is in minerals, plants, animals, and human beings with more and more sophisticated degrees of complexities. Schelling writes, "Man is thus the redeemer of nature towards whom all its archetype strive." 36 The hierarchy finally "ends with the most sophisticated forms of life, such as the selfconsciousness of the transcendental philosopher and the creativity of the artistic genius itself." 37 The latter's awareness of nature is nature coming into the utmost awareness of itself; the artist's creative power is the realization of the highest organic power inherent in nature. Nature and human beings, thus, mutually implicate one another; the latter can be seen as the means as well as the ends for nature and vice versa. This does not imply, among other things, a mere idealism of the Fichtean kind, where the identity of the subject and object is located in a transcendental subject. Rather, the "identity", which "precedes all antitheses" is located in an absolute "indifference," which is "a unique being, apart from all antitheses, in which all distinctions break up." 38 This groundless infinite being is a single infinite substance, and is the same whether interpreted subjectively or objectively. So there is no preference of human beings over nature or vice versa.

Thus, a sense of finitude is restored by the non-subjective approach of the Romantics, which does not attribute any privileged ontologicalmetaphysical status to human beings. Whereas Kant privileged the latter by contrasting human freedom with natural causality, the Romantics avoided such subjectivism. Insofar as they attribute any special status to human beings, it lies in their claim that the final purpose of nature is realized in humans, even though the existence of nature does not depend on the being of humans. So in a sense, they achieved what Kant achieved by focusing on the limits of human existence, without subscribing to his subjective presuppositions.

But what becomes of freedom? Kant had to rely on dualisms to make room for human freedom. If the dualisms are overcome, what do the Romantics have to say about freedom? If nature does not follow merely mechanical laws, the whole relation between necessity and freedom has to be rethought. Schelling notes:

The irrational and accidental element which reveals itself as connected with what is necessary in the formation of all beings, especially organic ones, proves that it is not only merely a geometric necessity which operated here, but that freedom, spirit and self-will played their part too. To be sure, wherever passion and desire are, there is already a kind of freedom. ${ }^{39}$

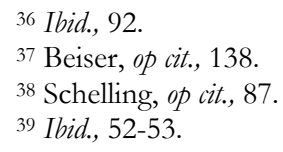


The presence of living spirit in nature is already a sign of freedom. The organic concept of nature implies freedom. Even though, in nature, each organism implicates one another, this condition does not preclude freedom, but presupposes it. Necessity and freedom are reconciled in such a way that true necessity is the same as true freedom. It is not just a question of saving freedom by making actions totally accidental in the face of determinism. Both these alternatives, Schelling argues, "are alike ignorant of that higher necessity which is equally far removed from accident and from compulsion or external determination but which is, rather, an inner necessity which springs from the essence of the living agent itself." $" 40$ There is freedom when the action is due to an inner necessity, that is, when the compulsion belongs to the nature of the organism itself. The notion of self-sufficiency, which is attributed to the organic concept of nature as a whole, ensures that freedom and necessity are reconciled. Passion and desire, as being indicative of freedom, and an inner necessity springing from the essence of the living agent itself - bringing these two together, I conclude, captures the quintessential nature of Romanticism.

An organism is not free as part of nature, but "it is free in its unity with nature as a whole." 41 If the organism as an individual self falls under the rule of necessity, the same organism as the universal self, that is, as representing the whole, partakes in freedom. Freedom, like reason, is not possessed by human beings alone. In fact, human beings do not even possess freedom like a property, but rather freedom determines the essence of human beings. Also, the notion of "individual personality" plays a vital role here, as Schelling explains in his treatise on freedom, but we will not go into this issue here. It is sufficient to note that for Schelling, "In original creation ... man is an undetermined entity ... he alone can determine himself ... [he is] free and himself eternally beginning." 42 The self becomes truly free when it recognizes its identity and harmony with nature.

\section{Conclusion}

It was my intention in the final paragraphs to provide a quick glance of how the question of freedom is handled by the Romantics. And my overall aim was not to capture all the various complex differences between Kant's philosophy and that of Romanticism, which would require taking into account the different arguments for human freedom that Schelling gives, and the related issue of the possibility of evil. The main purpose of my paper was merely to point out the subtle, but decisive, conceptual shifts introduced by the Romantics' notion of "organic nature" to Kantian philosophy. In pointing this out, we saw the different ways in which the philosophy of German Romanticism still maintained its Kantian heritage (for example, in its intentions

${ }^{40}$ Ibid., 61.

${ }^{41}$ Beiser, op cit., 151.

${ }^{42}$ Ibid., 63-64. Schelling seems to imply further that each individual determines himself in accordance with "the intelligible essence of [his] specific being." See ibid., 62. 
to retain a sense of human finitude), and the various ways in which this philosophy went beyond or transgressed some of the key principles of Kantian philosophy, such as its "subjective" presuppositions, its dualisms, and its contention that the concept of "natural purpose" may not be used constitutively. Only through this complex relation to Kant's philosophy, could Romanticism introduce a new kind of "dogmatism" to their philosophy, a "dogmatism" that was very influential on much of European thought that followed.

\section{Department of Philosophy, Rice University, United States}

\section{References}

Beiser, Frederick. C, The Romantic Imperative: The Concept of Early German Romanticism. (Cambridge, Massachusetts: Harvard University Press, 2003).

Kant, Immanuel, Critique of Judgment, trans. by J.H. Bernhard (New York: Prometheus Books, 2000).

Kant, Immanuel, Critique of Pure Reason, trans. by Norman Kemp Smith (New York: Palgrave Macmillan, 2003).

Schelling, F. W. J. von, Of Human Freedom, trans. by James Gutmann (Chicago: The Open Court Publishing Company, 1936). 